\title{
Horizonte político de la religión en perspectiva de la democracia ${ }^{1}$
}

\author{
Political Horizon of the religion in the perspective \\ of democracy
}

Guillermo A. Zapata Díaz ${ }^{2}$ Pontificia Universidad Javeriana, Colombia

Recepción: 13 de julio del 2018

Evaluación: 18 de septiembre del 2018

Aceptación: 20 de octubre del 2018

\footnotetext{
1 El presente artículo es el resultado de la investigación realizada por el semillero de filosofía de la religión que dirigió el autor de este texto.

2 Doctor en Filosofía, Licenciado en Filosofía y Letras, Magíster en Teología, Magíster en Estudios políticos y Magíster en Bioética. Profesor titular de la Facultad de Filosofía de la Pontificia Universidad Javeriana. Miembro del grupo de investigación Problemas filosóficos, adscrito a la Facultad de Filosofía de la Pontificia Universidad Javeriana.

Correo electrónico: gazapata@javeriana.edu.co.
} 


\title{
Resumen:
}

La política y la religión en occidente en la perspectiva de la democracia y desde horizonte del cristianismo, siempre han estado estrechamente relacionadas, en tanto ambas dependen de la manera en la que el hombre se ve a sí mismo y al mundo que lo rodea. Pero una de las características principales de la democracia, el sistema político mayormente aceptado en el mundo de hoy es su secularización. La democracia ya no permite tronos, y la religión ha sido reducida a una posibilidad de tantas que tienen los individuos al momento de elegir cómo quieren vivir sus vidas. Pero todo sistema político implica una religión diferente y viceversa. La democracia no es, de hecho, el momento del fin de la religión, sino una reconfiguración absoluta de la experiencia religiosa que podría llegar a ser considerada la más auténtica de todas. Investigar la mutua dependencia entre política y religión a partir de la cosmovisión que el hombre tiene de sí mismo en el contexto de la democracia asumiendo el desafío planteado a la libertad religiosa desde el horizonte político que se propone como tarea el camino de la paz.

Palabras clave: religión, democracia, libertad, trascendencia, sí mismo

\begin{abstract}
:
Politics and religion in the western culture, in the perspective of democracy and from the horizon of christianism, have been closely interwined, because both depend on how mankind see himself and the world around him. However, one of the main characteristics of democracy, the most commonly accepted political system in the world nowadays, is its secularization. Democracy does not allow thrones, and the religion has been reduced to one of many possibilities that individuals may choose as a way of living their lives. Next, the whole political system implies a different religion and vice versa. Democracy is not, in fact, the moment of the end of religion, but a complete reshaping of the religious experience that could become the more authentic of all. To examine the mutual dependence between politics and religion from the worldview that humanity has upon himself in the context of democracy assuming the proposed challenge to religious freedom from a political horizon that sets as task the guidance towards peace.
\end{abstract}

Keywords: religion, democracy, freedom, transcendence, self. 


\section{Horizon politique de la religion dans la perspective de la démocratie}

\section{Résumé:}

La politique et la religion en Occident dans la perspective de la démocratie et à l'horizon du christianisme ont toujours été étroitement liées, dans la mesure où toutes deux dépendent de la façon dont l'homme se voit lui-même et voit le monde qui l'entoure. Mais l'une des principales caractéristiques de la démocratie, le système politique le plus largement accepté dans le monde actuel, est sa sécularisation. La démocratie ne permet plus les trônes, et la religion a été réduite à l'une des nombreuses possibilités qui s'offrent aux individus lorsqu'il s'agit de choisir comment ils veulent vivre leur vie. Mais tout système politique implique une religion différente et vice versa. La démocratie n'est pas, en fait, le moment de la fin de la religion, mais une reconfiguration absolue de l'expérience religieuse qui pourrait être considérée comme la plus authentique de toutes. Étudier la dépendance mutuelle entre la politique et la religion basée sur la cosmovision que l'homme a de lui-même dans le contexte de la démocratie en assumant le défi posé à la liberté religieuse, à partir de l'horizon politique se proposant comme tâche le chemin de la paix.

Mots-clés: religion, démocratie, liberté, transcendance, lui-même

\section{Horizonte político da religião em perspectiva da democracia}

\section{Resumo:}

A política e a religião em ocidente na perspectiva da democracia e desde horizonte do cristianismo, sempre tem sido estreitamente relacionada, entanto as duas dependem da maneira em que a homem se vê a si mesmo e ao mondo que o rodeia. Mas uma das características principais da democracia no sistema político maiormente aceitado no mundo de hoje é sua secularização. A democracia não permite trones e a religião tem sido reduzida a uma possibilidade de tantas que tem os indivíduos ao momento de escolher como querem viver suas vidas. Mas todo sistema político implica uma religião diferente e vice-versa. A democracia não é, de fato, o momento do fim da religião, senão uma reconfiguração absoluta da experiencia religiosa que poderia chegar a ser considerada a mais autentica de todas. Pesquisar a mutua dependência entre política e religião a partir da cosmovisão que a homem tem de si mesmo no contexto da democracia assumindo o desafio proposto como liberdade religiosa desde o horizonte político que se propor como tarefa no caminho da paz.

Palavras-chave: religião, democracia, liberdade, transcendência, si mesma 
La paz [...]. Está fundada sobre el reconocimiento de los derechos naturales y esenciales de la persona humana y se construye en la justa satisfacción de las necesidades de todos. Necesidades de vida, de amor, de libertad, de trabajo coherente con las propias inclinaciones, del trabajo adecuadamente retribuido, del bien estar, de comunión, de Absoluto...Es por consiguiente una paz viva, creadora, gozosa, que nace de las relaciones ordenadas con nosotros mismos, con el prójimo, con lo trascendente (Martini, 1992, p.11).

Hoy se hace referencia al retorno de la religión. Aun en medio de una sociedad pluralista, laica, de nuestra era digital, es muy posible que la religión no sea meramente asunto del pasado. La religión sigue reafirmándose no sólo desde su sabiduría ancestral, también lo hace desde su aporte milenario a la identidad de la humanidad, y desde la esperanza que anima la búsqueda de lo más plenamente humano, puesto que "la nueva perspectiva trascendente y normativa creada por el discurso religioso según el cual "algo mejor, aún es posible""' (Aguirre, 2015, pp. 29-433). Esta esperanza de posibilidad abre a la religión el horizonte de lo utópico realizable, sin olvidar el sentido crítico que ocurre en la esfera pública de la discusión.

Por otra parte, tanto hoy como ayer, es posible notar que entre religión y política en Occidente, se abre un camino común de humanización a partir de la búsqueda conjunta que ambas pretenden del bien común para todos. Aunque para algunos -Feuerbach, Nietzsche, Benjamin, Horkheimer, Agamben, Vattimo, Habermas- la esperada liberación que prometía la religión no produjo el resultado esperado de su éthos afirmativo liberador de toda injusticia. A pesar del desencanto que experimenta el hombre moderno, las religiones continúan movilizándose desde su núcleo más íntimo hacia una justicia y liberación más auténticas inspiradas en el diálogo del hombre con la divinidad. Tanto la religión como la política tienen la mirada puesta en el horizonte común de una humanidad más justa, equitativa y liberada ${ }^{4}$. La justicia está presente en la mira no sólo de la religión, sino también de las

Todas las comillas y cursivas que aparecen en las citas pertenecen a los autores referenciados.

4 Si bien es cierto que nuestro objetivo en este artículo se centra en la civilización occidental, existe hoy un interés creciente por repensar la democracia en el Oriente. Louis Espósito y Tamara Sonn, en Islam and Democracy after the arab Spring (1996), reflexionan cómo el posible autoritarismo secular en el Islam político afronta las cuestiones relacionadas con la libertad, la igualdad, la justicia económica, la participación democrática y la relación entre el Islam y la democracia en diversos países. 
instituciones, como lo asevera J. Rawls ${ }^{5}$ en su texto Teoría de la Justicia, al reinterpretar ya la intención del mismo Aristóteles del problema de la justicia como asunto de la comunidad que define al hombre como ser social por excelencia en varias de sus obras, especialmente en la Politica.

En la actualidad, a pesar de que a la religión se le haya remitido al mundo de lo privado, continúa asumiendo su tarea histórica de gestar la convivencia humana, aun en medio de las distintas creencias plurales que configuran nuestras sociedades contemporáneas. Por otra parte, si a la religión se le remitía al mundo de lo privado, al Estado se le delimitaba el espacio de lo público. El Estado, por principio, queda excluido de asumir alguna religión debido a su carácter plural. El Estado tampoco puede imponer ninguna cosmovisión única de sentido, lo que sí asume como tarea la religión, la cual continúa abriendo el horizonte de sentido para una sociedad desafiada por nuevas racionalidades, en especial por los argumentos provenientes del ámbito científico-técnico que, a juicio de Max Weber, producen el desencantamiento del mundo religioso e ingenuo. Este autor argumenta que nuestra razón científica se fundamenta en lo positivo de la ciencia y no en las fábulas de la mística.

De todos modos, en el camino hacia la construcción del sentido, podemos indicar que la religión tiene los recursos necesarios para realizar su aporte en el proceso de humanización de la sociedad secular, plural, democrática y libre en la perspectiva de que "siempre existe algo mejor por conseguir". La religión ha asumido como desafío responder ante la incapacidad que los Estados presentan para afrontar los nuevos movimientos religiosos antiseculares, anti-institucionales, pre-modernos y con tan débil configuración institucional. Esta débil configuración institucional es, a la vez, el reflejo de

5 El mismo Habermas subraya el aporte de Rawls a la democracia participativa: “(...) la reciente propuesta de Habermas referida al rol de la religión en la esfera pública de una democracia deliberativa se encuentra relacionada estrechamente con sus ideas sobre lo político". Como es sabido, la propuesta de Habermas sobre el rol de la religión en la esfera pública es presentada como una "corrección de la perspectiva de Rawls" (Aguirre, 2015, p. 36).

6 A partir de la relación entre religión y libertad, F. Múnera (2008, pp. 207-231), mediante de una lectura política sobre democracia norteamericana en Alexis de Tocqueville centrada en la libertad, concede a la religión la posibilidad de responder a las exigencias democráticas, con lo que anima a las sociedades en su proceso de moralización que rescata la posible grandeza de la persona humana. También es, al parecer, la visión de Habermas: “a saber, como una tensión entre la realidad del poder político (el factum de la fuerza) y cierta perspectiva normativa y trascendente según la cual “"aún existe algo mejor por conseguir"”' (Aguirre, 2015, p. 43). 
una religiosidad difusa que se expande como un archipiélago de cosmovisiones y galaxias de sentido, tan abiertas como carentes de unidad a las que no existe la presencia de ninguna autoridad que les regule y unifique (Scott, 2003, p. 6).

En nuestro mundo contemporáneo carente de unidad, el laicismo, el capitalismo y el totalitarismo cuestionan a la religión por su pretendida nostalgia del centro en la que estuvo situada en el pasado. Esta nostalgia del centro es también propia de los totalitarismos que registra la historia del pasado siglo XX, los cuales buscaron sustituir el papel y el poder de la religión, al implantar la presencia de lo político y su pretensión de absolutez propia de una cosmovisión religiosa unilateral, como bien lo asevera el pensador e historiador francés Marcel Gaucher en su obra La condition historique (2003, p. 251).

De todos modos, la relación entre religión y política no puede desconocer la delimitación y el desafío planteado por el Estado laico y pluralista. El Estado tiene como función ser el

(...) regulador de una convivencia entre ciudadanos poseedores de diversas orientaciones religiosas, existenciales o ideológicas no interviene a la hora de crear el sentido último de la realidad y de la vida; [El Estado laico] es por naturaleza, pluralista y neutral ante las distintas cosmovisiones, siendo así la mejor invención para crear convivencia entre las diversas creencias, ideologías y cosmovisiones. (Mardones, 2006, p. 3).

Hannah Arendt en su conocida obra La condición humana (1993) delimita el objetivo de lo político en el escenario del ser en común inscrito en la pluralidad y diversidad propia de todo lo humano. Es así como "mientras que todos los aspectos de la condición humana están de algún modo relacionados con la política, esta pluralidad es específicamente la condición de toda la vida política" (p. 22).

En la política delimitada en el escenario de la pluralidad, el Estado asume como su tarea más propia el vivir juntos, con lo que facilita el intercambio de hechos y palabras de quienes se consideran libres, autónomos e iguales. En principio, el Estado laico posibilita la igual participación de todos los ciudadanos entre sí y el encuentro positivo que proporciona los elementos básicos que permiten la solidaridad. El Estado facilita también la convivencia aun en medio de la discusión y la confrontación de las distintas cosmovisiones que se entrecruzan de manera crítica, al dinamizar la puesta en común de las 
lecturas plurales del mundo y del sentido; estas, a su vez, se van ampliando y enriqueciendo permanentemente. En el entrecruce de cosmovisiones y comprensiones, se abre un camino de conocimiento y simbolización del Estado y la sociedad civil siempre plural.

Siendo el Estado el garante de la convivencia civil, aunque no el único, a la religión le corresponde la construcción del sentido último de la vida trascendente que se inscribe en el proceso de la búsqueda por la identidad personal y plural de los pueblos y las culturas. Aunque existen pretensiones comunes del Estado y la religión relacionados con el vivir en común, también existen diferencias mutuas relacionadas con sus respectivas autonomías. Esto lo encontramos definido en la constitución Gozos y Esperanzas del Vaticano II, cuando diferencia: "en el terreno que les es propio, la comunidad política y la Iglesia son independientes una de otra" (Concilio Vaticano II, 1965, p. 3). Sin embargo, en esta autonomía y diferencia encontramos presente el espacio de tensión y de enriquecimiento mutuo.

Autonomías y búsqueda en común conservan una tensión permanente que le viene no sólo de la noción tradicional de política, sino también de una revisión más moderna de este concepto. Para Habermas, la noción tradicional de política "debe ser entendida de una forma que sin volver a sus raíces religiosas, no las niegue, ni se vea incompatible con sus discursos religiosos que puedan aportar importantes intuiciones morales para todos los problemas actuales". (Aguirre, 2015, p. 43). Tanto la religión como la política van perfilando la identidad de las personas y de los pueblos a partir del concepto de laicidad. Para delimitar el concepto de laicidad, partimos de las conclusiones de Marcel Gaucher al señalar que el aporte de las religiones al proceso de identidad dentro de la tradición religiosa se establece a partir de la distinción entre laicidad ingenua y laicidad inteligente (Gaucher, 2003).

Esta última distinción es la más adecuada, por su criticidad, para alcanzar una sana convivencia de los ciudadanos en el espacio público de aparición y de convivencia común delimitado por la discusión, el intercambio y la negociación de opiniones. Esta laicidad inteligente es corroborada por Habermas que señala para la política "como el medio de autodeterminación democrática" de los ciudadanos, a partir de "su disposición para implicarse en la acción colectiva, y la conciencia de que los ciudadanos pueden determinar colectivamente las condiciones sociales de su vida por medio de la acción solidaria, [que] se debilita bajo la fuerza de los imperativos sistémicos como el capitalismo moderno" (Habermas, 2011, pp. 23-24). 
La tensión entre secularismo y democracia se debe a que la religión ya no desempeña las funciones públicas que realizaba antes, asunto que guarda relación con el giro subjetivo que ha dado la humanidad en la modernidad. Si bien la religión abre el horizonte moral basado en la relación fraterna y en la simetría al interior de la comunidad humana, la política está centrada en la lucha asimétrica -iguales en cuanto diferentes-por el poder a partir de la discusión y la confrontación política de los intereses contrastantes que exigen argumentación, retórica y juicio político. Esta lucha asimétrica se da precisamente en la democracia en donde "la silla del rey está vacía". Sin embargo, no podemos ignorar la influencia que ha ejercido la religión en la sociedad civil, ni el aporte que ha tenido en la construcción de la identidad histórica de los pueblos, los individuos y los grupos que deciden orientar y construir su vida desde un determinado horizonte de sentido y de valores culturales.

La laicidad se inscribe en el universo del poder político. En este universo del poder político, la secularización es el proceso complejo en una sociedad que se despliega en sus diferentes esferas, tales como la religiosa, la institucional, cultural y política. Si bien la laicidad se inscribe directamente en el universo del poder político, la secularización ${ }^{7}$ puede delimitarse como el proceso complejo de una sociedad configurado en las diferentes esferas: religiosa, económica, institucional, cultural, política, etc.

Desde la autonomía -y a la vez desde la diferencia- tanto religión como política no se verían reducidas a la simple división entre lo público y lo privado. Por otra parte, la religión hoy tampoco es calificada como irracionalidad y puro sentimiento, a no ser en algunos casos de fanatismos exacerbados que pretenden orientarse en motivaciones religiosas. Reducir la religión y la política al binomio público y privado es desconocer el problema de fondo de la fuerza política de la religión en medio de la sociedad política. Desde el punto de vista de la racionalidad, tanto lo político como lo religioso tienen sus argumentos y fundamentos propios. Es así que nadie posee la exclusividad de la racionalidad, como bien lo afirma Jürgen Habermas en su libro El futuro

El secularismo, visto desde el fenómeno del pluralismo, conlleva una complejidad y virtualidad ética y política impensada, en donde la razón moderna busca justificar un "retorno de la religión" en la "sociedad postsecular" a pesar de la negación de toda virtualidad ética y política de la religión en la esfera pública. La democracia insiste no tanto en la verdad cuanto en la solidaridad siguiendo a autores contemporáneos: Vattimo, Habermas, Rorty. Hoy se habla no sólo de lo secular, sino de lo post-secular. Para esto véase a Diego Bermejo (2016, pp. 219-256). 
de la naturaleza humana. Allí señala que es posible "mantener la distancia frente a la religión sin cerrarse a la perspectiva de ésta" (2002, p. 144). Sólo intercambiando las diferentes perspectivas y argumentando sus distintas pretensiones, religión y política pueden acercarse a su intención de delimitar la justicia y la libertad.

El Estado y la democracia no pueden prescindir de dar razón por los valores vinculados a las concepciones del mundo, al sentido de la vida y la muerte. Tampoco la religión puede desentenderse de las políticas concretas del Estado. Ni la religión ni el Estado pueden ser indiferentes a la pregunta por la justicia y la defensa de los derechos de las minorías.

Una laicidad ingenua puede llegar a ser laicidad de inteligencia critica ejerciendo su derecho a pensar y juzgar críticamente, al establecer una colaboración conjunta que permita poner en común los argumentos que justifiquen su convivencia. Por su parte, el ciudadano consciente es el protagonista de la democracia participativa a través de su acción y, en concreto, de su juicio político (Zapata, 2014, pp. 313-335).

De todos modos, bien podemos advertir que la secularización pretende desactivar la fuerza dinamizadora de la religión en el proceso de la construcción de la identidad del individuo y la sociedad. En cierta medida, lo secular pretende, como su nombre lo indica, un proceso de mundanización de la religión, la cual, al perder su protagonismo en la sociedad, corre el peligro de ser relegada al olvido por su elemento ilusionador, el cual, según la crítica de los maestros de la sospecha-Marx, Nietzsche, Freud-altera la verdadera realidad y la transforma en fantasía. Este destino lo correría la religión si no asume un compromiso ético-político a favor de la justicia y de la libertad.

Para la mentalidad científico-técnica, la función que antes realizaba la religión en las sociedades antiguas de unificación de la sociedad, tampoco la cumple el Estado moderno por la crisis de la democracia. Aunque la democracia se delimita en su propio interior desde la pluralidad que la constituye y está centrada en la discusión de los intereses diversos, no puede perder su tarea de acentuar las diferencias en medio de la igualdad de oportunidades para todos. Al reconocer y proteger la libertad individual de cada ciudadano -y mantener un poder colectivo y participativo- el sujeto de las democracias actuales está completamente inmerso en su propia subjetividad y no tiene interés por lo público. Esta carencia de interés por lo público se debe a que la visión del sujeto, y cómo este se entiende a sí mismo, ha cambiado: 
Hemos asistido a un cambio del sujeto. Las nuevas emancipaciones del individuo tienen un claro sabor a desposesión y desvinculación. Predomina un individualismo que propone la realización de sí de forma original y única en un mundo regido por enormes mecanismos anónimos, como el mercado, que nos uniforman. Este nuevo individualismo está centrado en sí. Una suerte de privatización que sólo parece buscar el goce y la satisfacción propias. (Mardones, 2006, p. 217).

La visión del sujeto moderno se percibe en un campo desolador no sólo para la religión, sino también para la democracia por su individualismo, aislamiento y anonimato. Tanto la religión como la democracia ya no tienen su función central dentro de la sociedad contemporánea. La misma democracia se ve tan amenazada como la religión por el creciente proceso de individualización que mina tanto la solidaridad como el poder vivir en común propio de lo político y de la política, puesto que acrecienta la indiferencia al debilitar el talante participativo de la democracia.

El sociólogo Alain Touraine en su texto Qué es la democracia (2001) inicia su reflexión acerca de los orígenes de este sistema político y los problemas que afronta desde su aparición en los tiempos modernos. Hace referencia a la novedad de la democracia que hoy se ha generalizado como la forma normal de organización política y cuya economía es la economía del mercado. La democracia es delimitada por tres principios institucionales, a saber: es un sistema que está constituido por unas reglas que determinan quién está autorizado a tomar las decisiones; busca que la mayor cantidad de personas participen en la toma directa o indirecta de decisiones; y, finalmente, se asegura de que estas elecciones sean reales.

Ahora bien, si en la sociedad secularizada el sujeto está tan inmerso en sí mismo, le es difícil construir una comunidad política que le exija participar argumentativamente de acuerdo con los lineamientos del espíritu democrático. El mundo ha cambiado de tal manera en el último siglo que le es difícil al sujeto mirarse a sí mismo, a pesar de que la democracia sea el sistema político en el que los sujetos pretendan defender su libertad, para lo cual procuran asociarse.

Sin embargo, es opinión común considerar a la democracia como el mejor sistema político en el que los seres humanos se relacionan para defender su intención de querer vivir juntos, especialmente comparado con los totalitarismos y monarquías que durante tantos años gobernaron las 
sociedades. Ahora bien, a nivel religioso, parece ser una gran ventaja el no estar obligado a pertenecer a ninguna doctrina religiosa y poder libremente elegir qué creencias tener. Pero, en definitiva, la democracia, como cualquier otro sistema, trae consigo tanto ventajas como desventajas que van más allá del problema planteado por Mardones alrededor de la preservación de la unidad.

La consigna de las religiones encaminadas a la construcción del sentido último del ser humano consiste en admitir su carácter trascendental. El hombre no es sólo su realidad material, sino que tiene en su esencia una dimensión metafísica: "somos seres de creencia" (Mardones, 2006, p. 217). Sin embargo, a partir de los estudios del historiador y sociólogo francés Marcel Gauchet, nos remite a que en la salida de la religión del mundo secularizado, a causa de las distintas visiones sobre la democracia, surgen sinnúmero de desafíos aún no resueltos por la misma religión. En este horizonte secularizado cabe preguntarse: ¿qué sucede con la dimensión trascendente del hombre en el contexto de la democracia? ¿Hay algún espacio para la religión en el contexto político de una democracia? Y frente al sistema capitalista que parece comportarse con elementos traídos de la misma religión: ¿cómo se relacionan el capitalismo y la religión? ¿Cómo se comunica el hombre actual con lo trascendente?

Es bien cierto, por otra parte, que la misma democracia en el contexto de la secularización tiene enemigos, como son el individualismo a ultranza que proyecta el olvido del otro, el materialismo consumista centrado en el tener y la producción de víctimas acrecentada por desinterés y la insolidaridad. En el capitalismo, el homo consumens es el rey y se propone una competencia cercana a lo que nos plantea T. Hobbes, del hombre como lobo para el hombre, sumado al desarrollo del mismo capitalismo que requiere de nuevas reinterpretaciones, pues ya la mano invisible que lo controla no es ciertamente tan invisible. El deseo de poseer y tener se dispara de tal manera que el hombre mismo queda preso de sus propias creaciones. En este sentido surge la pregunta: “Cómo vivir la vida en un mundo desbocado?” (Giddens y Hutton, 2001, pp. 233-234).

Si bien la religión en $L a$ sociedad sitiada pretende liberar el deseo de trascendencia del hombre, en apertura a una economía del don y de la gratuidad, que le viene al hombre como modo de ser del espíritu, esta última se contrapone a la economía del capitalismo instalada en el dinamismo del deseo, y movilizada por la publicidad del tener para poder ser como modo 
único de realización personal (Bauman, 2004, p. 221). En la dinámica del tener, la sociedad queda dividida en los bandos poseedores y desposeídos, de los ricos y los empobrecidos. Si el centro de la sociedad es el tener, quedan los más por fuera del sistema y la masa de los excluidos y empobrecidos es cada día más numerosa, termina siendo eliminada como los residuos de una sociedad que produce ingentes cantidades de excedentes, entre ellos, los pobres mismos.

La secularización en su dinámica de des-religiosización, asumida por el capitalismo con su talante consumista centrado en el mismo individuo, pone también en jaque a la misma democracia, en la medida en que queda en suspenso su pretensión del bien común o, por lo menos, sus cadenas de intereses compartidos. Este olvido de la religión trastocada en consumismo va delimitando cada vez más un mundo cada día más inhumano.

Esta religiosización del consumismo centra al individuo en sí mismo y en una búsqueda compulsiva de novedades que no sólo señala la creatividad destructiva del capitalismo, sino que, en un mundo de necesidades y escasez con miles de muertos de hambre diarios, manifiesta una aberración y una insensibilidad insolidaria. Lo humano queda olvidado, marginado por la posesión momentánea y el despilfarro de objetos que no sirven para nada, sino para satisfacer un deseo. Una vida frágil y precaria orientada a la satisfacción instantánea (Mardones, 2006, p. 3).

La creencia de que la vida está cifrada en la satisfacción momentánea niega a la vez la pretendida libertad de la democracia económica, incluso para quienes no tienen expectativas de sentido dentro de su mundo de la vida. El único sentido es lo inmediato y perecedero: "La moderna pérdida de creencias, que afecta no sólo a Dios o al más allá, sino también a la realidad misma, hace que la vida humana se convierta en algo totalmente efímero" (Byung-Chul, 2012, p. 28) y vacío.

Ahora bien, si se anula el éthos democrático participativo, la sociedad moderna niega la organización comunitaria y deliberante que se orientaría por el consenso, la negociación y los pactos. Es precisamente la actitud deliberante y consensual la que posibilita a la democracia tomar y asumir las decisiones a través de los mecanismos del poder. Al ir en contra de su acento humanista, la democracia queda en entredicho por las opciones que anteponen al individuo antes que al bien común de todos (Geffré, 2005, pp. 98-110). La opción por lo individual cancela el diálogo con todos los testigos de la conciencia universal, aunque frecuentemente no religiosos. Sin embargo, no favorecen la escucha no quedando espacio para la argumentación y el 
intercambio de puntos de vista. De este modo, el diálogo queda anulado. Igualmente, al negar la alteridad, se anula la relación con la trascendencia y la escucha del otro y del totalmente otro, tan propio de lo supra-mundano y de la fe religiosa.

\section{Mutua implicación entre la política y la religión}

En una mirada hacia los antecedentes de la relación entre política y religión, es posible establecer la implicación mutua entre los dos componentes de lo político y lo religioso, a tal punto que un cambio en lo religioso altera a su vez el horizonte político. Esta relación entre política y religión, anota nuevamente M. Gauchet (2003), es de tal magnitud que: "[e]l cambio del aparato de poder en la comunidad supone un giro o revolución religiosa. Todo cambio político supone un cambio de pensamiento y la religión ha sido en la historia de la humanidad el lugar reflexivo por excelencia” (p. 210).

Esta implicación política de la religión se puede apreciar en los grandes cambios que han tenido lugar a lo largo de la historia, como se ha dado a través del paso de una sociedad primitiva a otra más moderna con el establecimiento del Estado y la democracia. Aunque en las sociedades primitivas la religión y la organización social se identifican absolutamente y se explicaban el sentido de su vida desde sus mitos referentes a los tiempos ancestrales, la aparición del Estado dio un gran salto de la sociedad primitiva hacia el interior de la comunidad civil. Esto supuso un cambio de pensamiento y racionalidad, una alteración de las relaciones de poder y, por consiguiente, implicó una manera distinta de gobernar.

El surgimiento del Estado moderno trae consigo una nueva manera de conciencia y, en consecuencia, una nueva forma no sólo de verse a sí mismo, sino de entenderse en relación con el mundo, con los otros y con la sociedad. Esta nueva forma de conciencia produce en la política un nuevo acento de la subjetividad del sujeto político. En relación con la religión, esta subjetividad coincide con el nacimiento del monoteísmo judío y la importancia que este le dio a sus profetas. Aquellos -los profetas del pueblo judío- anuncian un cambio radical en la forma de entender la relación con lo sagrado, a tal punto que lo divino mismo se encarna en la historia de la humanidad. Esta es la visión teológica de un Dios que se ha revelado en la historia y que ha influido en la visión cristiana del sujeto que se deja interpelar por su Dios en la historia. Se puede afirmar que este es precisamente el aporte del cristianismo a la subjetividad. El Dios mismo encarnado en la historia revelando la voluntad divina. 
Sin embargo, esta encarnación de Dios en la historia de la humanidad, de acuerdo con la lectura del cristianismo, hace de su fundador un profeta que se encarna y cumple una misión desde los excluidos, los marginados, los pobres del Señor que la biblia nombra con el término «anawin», palabra que nombra a los excluidos tanto política, religiosa, como socialmente; esta encarnación de Dios, afirmábamos, se muestra ante la mirada creyente como invitación a interpelar y mirar en ese otro al totalmente Otro. En este otro se da la teofanía o mostración de Dios. La teofanía se transforma en antro-pofanía, encarnación de lo divino en lo humano. Este señalar a un más allá del dominio de los hombres tiene un carácter sagrado que contrasta con el más acá de lo humano. Pero la encarnación de lo divino se realiza aquí en el reverso de la historia. Aparece un Dios totalmente otro que señala la diferencia entre el más allá del dominio de los hombres y este más acá (Mardones, 2006). Este gran cambio en la manera de leer la historia no sólo marca el inicio de un nuevo tipo de religiosidad, sino que también es la primera advertencia de un camino hacia la democracia. La divinización de todos, la dignidad de todos en la comunidad plural, aunque "todos somos lo mismo, es decir, humanos, y por tanto nadie es igual a cualquier otro que haya vivido, viva o vivirá" (Arendt, 1993, p. 22).

Según esta interpretación histórica, el cristianismo concedió una gran fortaleza a la dignidad y al respeto humano de cada quien y, consecuentemente, se consolidó como el mediador entre la sociedad cristiana y Dios. La misma comunidad creyente se definía como pueblo, asamblea de Dios. Pero, a pesar de haber conquistado históricamente un enorme poder, el cristianismo encuentra su declive. La división al interior del cristianismo hace surgir el protestantismo. Al perder la unidad, el mismo cristianismo va perdiendo la influencia y la unidad política de antes.

La emergencia de la subjetividad moderna tiene sus antecedentes en el aporte del filósofo francés Renato Descartes (1596-1650), considerado como el pensador que abre la consideración del hombre para el pensamiento moderno. Descartes, aún influenciado por la escolástica, interrelaciona al sujeto creyente con el sujeto cognoscente. El sujeto cognoscente duda metódicamente en búsqueda de certezas y se convierte en sujeto político al exigir al Estado no sólo sus derechos, sino también su libre autodeterminación y autonomía que da un paso decisivo caracterizado por "un cambio reflexivo, una forma consciente más que espontánea de integración social", que bien podemos denominar hoy el uso práctico de la razón en una democracia participativa (Habermas, 2011, p. 26). 
El acento en el sujeto, y en su razón, va promoviendo un alejamiento de lo divino y va ocasionando la "salida de la religión", al quitarle las funciones públicas que ejercía, con lo que se encamina hacia una sociedad que cada vez acude más a la comunidad misma y a la libertad de sus integrantes para determinar cómo organizarse legal, política y moralmente.

En la gestación de la autonomía, la democracia pasa por varias crisis e incluso se ve también amenazada por la tentación de totalitarismos ${ }^{8}$. Estos - los totalitarismos- pueden presentarse como las "religiones seculares", que en su intento por restablecer el "molde unitario y cosmovisional" de la herencia religiosa, ofrecen a cambio de la "salida de la religión", la autonomía de lo humano que destruye cualquier pretensión de regreso a la unidad original de la sociedad.

Esta especie de "salida" a la "mayoría de edad", al ejercer la autonomía de la razón - diría Kant en su carta Qué es la ilustración- lleva consigo el establecer la dignidad de lo humano justificada y fundamentada en la razón. Este sistema racionalmente construido ya no necesita de la religión para legitimarse ni para organizar la sociedad. En la modernidad hay una "ideología patológica nueva: la del individuo total" (Mardones, 2006, p. 218), y esto influye no solamente en el modo de ser de la religión en la actualidad, sino también en el de la política. La religión es vista ahora como corruptora de la sociedad. Según una lectura realizada por Hannah Arendt sobre el papel de la Iglesia según Nicolás Maquiavelo, "[e]l dominio religioso sobre la esfera secular (...) [es el que] corrompía al cuerpo religioso" (Arendt, 1993, p. 83). La religión encarnada en el cuerpo religioso sería así la responsable de dañar el cuerpo político y este era precisamente el temor de Maquiavelo.

La separación entre lo religioso y el Estado, sumado al acrecentamiento de la individualización extrema, ha llevado a una despolitización de la política, porque lo propio de la política está cifrado en el vivir juntos de la comunidad humana, comunidad que al ser atomizada por el individualismo dispersa a los ciudadanos y sus intereses, puesto que la política trata del estar juntos y

8 Si bien la organización política tiende al exceso, precisa de mecanismos de control y una sociedad civil vigorosa. A esto contribuye la religión. Ella, desde su especificidad, ejerce una función correctora y de fundamentación, pues también la democracia puede caer en el despotismo, al fomentar el conformismo social o el fundamentalismo. La democracia, de la mano del laicismo, puede incurrir en este abuso y erigirse en algo absoluto y absorbente. Por el contrario, la religión le ayudará a trabajar por el bien común. (Martí, 2010, pp. 547-591). 
los unos con los otros de los diversos; sin embargo, los hombres se organizan políticamente según determinadas comunidades esenciales en un caos absoluto, o a partir de un caos absoluto de sus diferencias (Arendt, 1997, p. 45). En este desorden de las diferencias, muchos quedan excluidos perdiendo no sólo el interés sino cayendo en la más cruda apatía al no ser tenidos en cuenta.

Asumir la dinámica de lo político en este contexto individualista, susceptible de caer en el caos, debe partir de la pregunta sobre cómo establecer el espacio de lo público que asuma la pluralidad de intereses, en donde el único interés no sea la ventaja individual. De todos modos, es posible establecer que si todavía queda un resquicio de lo humano, aún desde una posible metafísica de la finitud y de la subjetividad, la religión pueda sobrevivir como una de las múltiples identidades posibles. Asunto este incluso más problemático en el caso de la democracia que, por definición, asume el conflicto de identidades y la radicalización de las diferencias, lo que puede llevar al fracaso y la decadencia de la democracia como lo asumen algunos teóricos de la tercera generación de la Escuela de Frankfurt ${ }^{9}$.

Para finalizar nuestra reflexión sobre el horizonte político de la religión, desde la perspectiva de la democracia, podemos considerar una crítica a este concepto de "la salida de la religión" escrita por el jesuita francés Paul Valadier. La así denominada "salida de la religión", según Gauchet, no sólo es "salida" sino el final de la religión. Valadier señala que esta hipótesis pretende llegar más lejos de lo que afirma, puesto que se puede perfectamente demostrar la aparición de una sociedad sin religión llegando con ello a demostrar, al mismo tiempo, que con ella se plantea también el fin de la religión. (Citado por Moscoso, 2006, p. 75). Sin embargo, lo que notamos no es tanto el fin de la religión como se pretendía, sino su regreso, pues la religión reaparece y con mayor insistencia.

Para poder sostener la teoría de un "fin de la religión" o por lo menos de su "salida" de las funciones públicas, estos autores franceses adoptaron una teoría que tal vez hoy está un tanto superada, pues se determina en esta

9 Para Lutz Winger, profesor en el Instituto Federal Suizo de Tecnología de Zúrich, el concepto de democracia se ha vuelto obsoleto, anticuado, puesto que las teorías de sistema entienden la política como el medio de autodeterminación democrática, con lo que la hace imposible y superflua en su sentido clásico, por lo que no corresponde con la realidad ni responde a los desafíos de los ciudadanos concretos. (Habermas, 2011, p. 24). 
teoría una única esencia de la religión, la cual tuvo su máxima expresión en lo que fue una "religión pura" y primitiva (el cristianismo). "La religión pura es aquella que muestra la "verdad de su eficiencia social", es el "momento de su dominio exclusivo" sobre lo social, marcado por la oposición al despliegue de la escisión" (Citado por Moscoso, 2006, p. 78). Pero Paul Valadier duda de que en algún momento de la historia, de hecho, haya habido una omnipresencia tal de la religión como lo sugiere Gauchet. De acuerdo a esto, la esencia de la religión sería entendida, en primer lugar, como "“rechazo por el hombre de su propia potencia de creador", y en una segunda ocasión por un tipo de organización que rechaza la división social" (Citado por: Moscoso, 2006, p. 78).

Esta fuerte crítica a las ideas de "salida de la religión" muestra que la falencia de estos planteamientos se encuentra en una visión muy estricta de lo que es la religión. El problema se encuentra, principalmente, en postular como esencia de la religión una de las formas en la que ésta se ha expresado a lo largo de la historia: el cristianismo. Al asumir esta crítica, se debe cuestionar el modo en el que el autor analiza la relación que hay entre religión y democracia en la actualidad. Para profundizar en esto, debemos, primero, aclarar qué es la democracia y, luego, preguntarnos qué es religión.

El Estado y la democracia no pueden prescindir totalmente de los valores vinculados a las concepciones del mundo, ni la religión puede desentenderse del todo de las políticas concretas del Estado; asuntos tales como la vida y la muerte y la defensa de los derechos de las minorías, requieren de diálogo y entendimiento. Se trata de pasar de una laicidad de incompetencia a una laicidad de inteligencia, con base en una colaboración conjunta, en función de la convivencia de los ciudadanos.

Algunos que aceptan la laicidad del Estado quitan la intervención de la Iglesia, aunque hay otros que pretenden redefinir el espacio cultural desde lo religioso, pero sin integrismos ni fundamentalismos.

\section{Disposición humana: algo mejor por construir.}

Si bien es cierto que la humanidad se ha acercado de muchas maneras, a lo largo de la historia del hombre a la religión, sus variadas maneras de encarnarse han sido pensadas y vividas desde las civilizaciones más antiguas hasta las miradas más contemporáneas. La religión representa un espacio en el que se implican la interioridad, la reflexividad para ir estructurando 
un compromiso histórico que permita encarnar las utopías realizables y llegar incluso a la "diplomacia como misericordia dentro de la inteligencia geopolítica" (Spadaro, 2016, p. 219). Como bien afirma el Papa Francisco: "Dios se manifiesta en una revelación histórica. Dios se manifiesta en el tiempo y está presente en el proceso de la historia. Esto da prioridad a las acciones que generan dinámicas nuevas (...) la misericordia se extiende a lo largo del tiempo orientando a la persona hacia un proceso de reconciliación" (Citado por Spadaro, 2016, p. 219).

La concreción de su compromiso histórico trascendente requiere del poder, ya sea moral, político, cultural, que motivan la acción cuya pretensión no es otra que la de vivir juntos. Esta convivialidad propia, tanto del espacio público como de la dimensión de lo sagrado, es el objetivo de lo político y de lo religioso. De este modo, un cambio en un nivel altera el otro. Un cambio en la religión altera lo político.

El fenomenólogo alemán de la religión, Rudolf Otto (1996), ha acuñado el término de lo numinoso, para delinear la "disposición o temple numinoso del ánimo, que sobreviene siempre que aquella [categoría de lo sagrado] se aplica" (p. 2). En este sentido, lo numinoso es la disposición que acompaña en cada ser humano lo inefable, lo absoluto e incondicionado como una especie de $a$ priori-independiente de la experiencia-, que se revela como perteneciente a la estructura de la condición humana. La búsqueda de lo absoluto acompaña la pregunta que todo hombre se hace por un ser superior que permite explicar toda la realidad desde la misma estructura del conocimiento humano, lo cual requiere de una racionalidad distinta a la racionalidad de la lógica, de la física, de las matemáticas, abierta a la comprensión de la libertad que en autores como Kant se inscribiría en aquel horizonte en que podemos pensar la libertad humana en el reino de los fines. La razón, al ser una sola, permite diferentes usos, y uno de estos es la racionalidad práctica que nos permite adentrarnos en fenómenos como la política, la ética y la religión.

Al pensar lo sagrado, y dentro de esta actitud fundamental o "disposición de ánimo", ingresamos en un espacio de comunicación y cercanía del hombre con Dios, con el mundo y con sus semejantes. Por otra parte, lo político delimitado como la instancia del poder, entendido no sólo como fuerza sino como concertación del vivir juntos, emplea como disposición de ánimo su deseo de comunicación e intercambio de argumentos e intereses. Además de la negociación, el pacto, la discusión y esclarecimiento de las diferencias. 
Si el poder desde lo político se delimita como la disposición del actuar juntos consensuado, como intercambio de hechos y palabras, en la dinámica de lo religioso, la palabra rito se contextualiza en el compromiso ético-político de las religiones, cuyo horizonte se inscribe en la dinámica de una esperanza realizada, aunque abierta a lo inefable en el futuro aún no consumado de la realidad histórica.

La religión comparte con la política el vivir en común de una pluralidad que, desde el horizonte de lo religioso, se abre a responder las preguntas sobre lo que nos cabe esperar, según aquella conocida intuición kantiana de que si la epistemología se ocupa de lo que me cabe conocer, la ética de lo que puedo hacer, mientras que la religión responde a la pregunta sobre lo que me está permitido esperar. De esta respuesta, toda religión quedaría enmarcada en el horizonte de la esperanza, de lo posible por construir, del más allá de la historia y de la pregunta por la justicia en el más acá del compromiso éticopolítico de la solidaridad. Aunque tocándose con asuntos de la política, la religión cultiva la fe como un sentimiento de dependencia de un ser superior, al originar no una sumisión pasiva sino una respuesta de compromiso ético, moral y político con la historia, que le conduce a la liberación de los poderes perversos. En este sentido, como afirma A. Heschel, "el hombre no está solo" (1976) porque ante lo sublime tiene la capacidad de desplegar la profundidad de lo inefable y de vivir la plenitud del espíritu humano en un diálogo ininterrumpido entre la criatura y el creador, entre Dios y el hombre. Este diálogo asume también la preocupación por el mundo, por su contexto histórico y geopolítico. La dimensión religiosa no olvida su compromiso y concreción de la realidad presente ${ }^{10}$.

Hoy la sociedad se basa en la pluralidad y, en consecuencia, en el tipo de experiencia religiosa. Aunque tiene sus vivencias y ritos, el horizonte innegable de la religión implicaría un compromiso ético-político ligado a la

10 Daniela Sorea subraya la importancia de las ciencias sociales en la relación religión y política. Sugiere, desde el enfoque holístico de la física contemporánea, plantear críticamente la relación entre religiosidad, secularización y contrasecularización, anclada en la posible determinación genética de la inteligencia, la religiosidad y la fertilidad (2017, pp. 93-106). Es posible abrir el espacio de reflexión entre religión y política a la postmodernidad y la globalización (Manolache, 2017, pp. 85-94). Por otra parte, hoy es impensable manejar los problemas ambientales contemporáneos sin la cooperación integral de religiosos, laicos, al generar un proceso de organización e identidad en cooperación y red desde su compromiso con el pluralismo religioso, con lo que se hace énfasis en la humanidad vista como parte integral de la naturaleza, una especie de religión terrapolitana de la Tierra. Al respecto, véase lo afirmado por Daniel Deudney (1998) y Bron Taylor (2010).

Zapata, G. (2019). Horizonte político de la religión en perspectiva de la democracia. 
lucha por la justicia, encaminada a la liberación de los excluidos de la tierra y al reestablecimiento de su dignidad humana, desde una gran cantidad de opciones éticas, políticas y morales. De acuerdo con Habermas, lo político sólo seguirá siendo importante,

en la medida en que se relacione la autocomprensión democrática y deliberativa de todos los ciudadanos bajo la cual todos somos miembros libres e iguales de la comunidad política donde nos concebimos a nosotros mismos, concebimos a los demás y esperamos ser concebidos por todos ellos, como autores y no como simples súbditos de leyes (Aguirre, 2015, p. 43).

La democracia supone, en su esencia, una forma nueva de religión o de relación con lo divino. El hecho de que debamos admitir la pluralidad de creencias no quiere decir que se haya acabado la religión y mucho menos que ésta haya perdido su importancia en la 'constitución' del hombre. Probablemente es todo lo contrario, porque sólo en la democracia el hombre es libre de ser sí mismo, de desarrollar sus capacidades y de ser verdaderamente auténtico, lo que incluye tanto su realidad material como espiritual.

¿Qué es esta dimensión trascendental y metafísica del ser humano? Karl Rahner ilumina la respuesta: "el hombre es la absoluta apertura al ser en general, o, para decirlo con una sola palabra, el hombre es espíritu. La trascendencia hacia el ser en general es la estructura fundamental del hombre" (1967, p. 73).

Preguntarse por el Ser en general es preguntarse por el ser del hombre, ya que hay una relación permanente y esencial entre ambos. En toda pregunta humana está implícita la cuestión por el Ser en general, pues el pensar humano va siempre acompañado de un saber anticipado y previo del ser, y esto es condición del conocimiento de las cosas particulares (Rahner, 1967).

El hombre no existe sino es como pregunta; tiene la capacidad de oído: puede oír la palabra de Dios que se le revela porque en su esencia está la posibilidad de recibir esta revelación. Su esencia es trascendente, no tiene su eje en su propio ser, sino que constantemente se abre a preguntarse por el infinito del Ser. Esta capacidad de escucha lo es también de respuesta, es una posibilidad de ser. Esto quiere decir, en otras palabras, que la posibilidad del hombre, que es da-sein (ser-ahí), de preguntarse por el Ser, es su capacidad de ser sí mismo y de auto conocerse. Lo divino es tan concreto que en el fondo lo que hacemos al hablar de ello es hablar de nosotros mismos como apertura. Como Rahner dice: 
El hombre es espíritu, es decir, el hombre vive su vida en un continuo tender hacia lo absoluto, en una apertura hacia Dios. Y esta apertura hacia Dios no es una mera incidencia que pueda, por así decirlo, darse o no darse en el hombre a discreción, que pueda darse aquí y allá, o no darse, sino que es la condición de posibilidad de lo que es y ha de ser el hombre y lo que es efectivamente siempre, aun en la más oscura vida de todos los días. Sólo es hombre por cuanto está siempre en camino a Dios, sépalo expresamente o no lo sepa, quiéralo o no lo quiera, puesto que siempre será la infinita apertura de lo finito hacia Dios (1967, pp. 89-90).

Lo divino y lo humano está completamente relacionado. Cuanto más se pregunte el ser humano por el Ser, cuanto más asuma su esencia preguntante, más se conoce a sí mismo. Y, cuanto más se es sí mismo, más se convierte en su propio ser. Como dice Rahner, "ser es de suyo conocer, y conocer es el estar consigo del ser de un ente -dado por necesidad juntamente con la constitución del ser- es su reflexividad sobre sí, su subjetividad" (1967, p. $60)$.

Esta reflexión de Rahner nos ayuda a comprender la subjetividad y la religión de una manera muy diferente a la usual. Ser sujeto, y serlo de manera cada vez más auténtica, implica preguntarse por el Ser, o sea, entrar en relación con Él, o, en otras palabras, hacer religión. Y lo más interesante es que ésta es una relación necesaria: cada vez que soy más yo mismo, conozco más el Ser y cada vez que conozco más el Ser, soy más yo mismo. La religión es así camino de humanidad.

\section{Conclusión}

Es importante nunca olvidar que el hombre siempre tiene el riesgo de caer en la inautenticidad. La mera existencia no es un camino directo hacia sí mismo y hacia el Ser, porque este se muestra por partes y nunca de manera absoluta. La verdad, el Ser, es un camino de mostraciones, un suceder, un acontecer.

Ser sí mismo implica ser coherente con la propia naturaleza. La naturaleza del hombre es variada y difícilmente definible. El ser humano es esencialmente apertura, pero su ser se muestra de muchas maneras: es un ser político, social, religioso, económico. Se conoce a sí mismo más en la medida en la que es, pero las condiciones de posibilidades de ser sí mismo también están delimitadas por el sistema político, cultural, económico en el cual está inscrito. Sólo la pregunta como algo abstracto no puede bastar para llevarnos al Ser en general, porque este se muestra de manera concreta. 
A veces pareciera que la historia del hombre es un camino hacia la subjetivación cada vez más profunda del ser humano. A pesar de que en un principio cuestionamos las posibilidades de la existencia de la religión en un sistema democrático y de la capacidad de este sistema de responder al problema de la unidad, ya que hemos profundizado en la naturaleza trascendental del hombre. En todo caso, una pregunta más acertada sería si acaso es la democracia, de hecho, el sistema que permite una verdadera relación con el Ser. Pues es este modelo político el que tiene como centro la preservación de la libertad, como un admitir y un respetar la capacidad que tiene cada individuo de ser él mismo y de auto determinarse en el contexto del vivir juntos propio de la vida política.

El hombre es más religioso en la medida en la que es más sí mismo. Y el ser más sí mismo sólo es posible dados los principios de la democracia. Independientemente de si efectivamente lo hace o no, éste es un sistema que proporciona las condiciones necesarias para que de hecho el ser humano pueda ser lo que es y quiere ser.

Con la modernidad cambió la forma en la que el hombre se ve a sí mismo. El nuevo pensamiento y las ideas que están tras la democracia implican también una reconfiguración de la vivencia religiosa en la comunidad, que ahora cada vez se da más desde el sí mismo, desde una búsqueda de autenticidad. Dentro de la autenticidad se descubre el verdadero sentido de la tolerancia, el reconocimiento del otro, el respeto por su dignidad, la motivación por un proyecto de esperanza y de transformación solidaria de la realidad, especialmente acogiendo al que requiere ser más promovido y protegido. Esto indica que no puede haber una salida de la religión de las funciones públicas y de la participación política y menos de la vida del hombre, porque ahora la religión se ha hecho concreta e, incluso, más auténtica.

Finalmente, hemos visto que si efectivamente hay una relación intrínseca entre la religión y la política, dado que ambas están estrechamente conectadas con la visión que tiene el hombre del mundo, y dada la naturaleza trascendente del mismo ser humano que es espíritu y apertura, entonces no se puede hablar de una salida de la religión de las funciones públicas en la democracia, sino de una reformulación de la experiencia religiosa que es una exigencia misma del énfasis en la libertad y la capacidad de autodeterminarse que tiene el hombre el día de hoy, en los proyectos incluyentes de una democracia participativa abierta a la fusión de horizontes y del empoderamiento de los creyentes que, como ciudadanos, cuentan con todo su derecho de expresar su visión del mundo, del hombre, de las cosas, desde la perspectiva de su fe comprometida con la realidad histórica. 


\section{Referencias}

Aguirre, J. (2015). Hacia un sentido democrático de "lo político": Jürgen Habermas y el rol de la religión en la esfera pública. Revista de Antropología y Sociología: Virajes, 17(1), 23-44.

Arendt, H. (1993). La condición humana. (Trad. R. Gil Novales). Barcelona: Paidós.

Arendt, H. (1997). ¿Qué es la política? (Trad. R. Salas Carbó). Barcelona: Paidós.

Bauman, Z. (2004). La sociedad sitiada. (Trad. M. Rosenberg y E. Zaidenwerg). Buenos Aires: Fondo de Cultura Económica.

Bermejo, D. (2016). Secularismo, religión y democracia. El giro democrático en el debate secularismo-religión. Pensamiento, 72(271), 229-256.

Byung-Chul, H. (2012). La sociedad del cansancio. (Trad. A. Saratxaga Arregi). Barcelona: Herder.

Esposito, J., Tamara, S., y Voll, J. (1996). Islam and Democracy after the Arab Spring. Oxford: Oxford University Press.

Frisk, K. (2015). Citizens of Planet Earth: The Intertwinement of Religion and Environmentalism in a Globalization Pespective. Journal for the Study of Religion, Nature and Culture, 9(1), 68-86.

Concilio Vaticano II. (1965). Gadium et Spes. Ciudad del Vaticano: Vaticana.

Gaucher, M. (2003). La condition historique. Paris: Stock.

Giddens, A., y Hutton, W. (Eds.). (2001). En el límite. La vida en el capitalismo Global. (Trad. M. L. Rodríguez Tapia). Barcelona: Tusquets.

Habermas, J. (2002). El futuro de la naturaleza humana ¿Hacia una eugenesia liberal? (Trad. R. Salas Carbó). Barcelona: Paidós.

Habermas, J. (2011). El poder de la religión en la esfera pública. (Trad. J. Carabante y R. Serrano). Madrid: Trotta.

Heschel, A. (1976). Man is not alone: A Philosophy of Religion. New York: Octagon Book. 
Gauchet, M. (2004). Un monde désenchanté. Paris: L'Atelier.

Mardones, J. (2006). Democracia y religión en un mundo laico: la salida de la religión y la crisis de la democracia. Nuevas teologías políticas: Pablo de Tarso en la construcción de Occidente, 209-228. Barcelona: Anthropos.

Martí, J. (2010). Democracia y religión: la aportación del cristianismo. Ius Canonicum, 50(1), 547-591.

Manolache, S. (2017). Postmodernity and globalization in the contemporary World. Brief Theological Considerations on Humans and Religions. Cross-Cultural Management Journal, 19(2), 85-94.

Martini, C. (1992). Non temiamo la storia. Roma: Piemme.

Moscoso, G. (2006). La democracia contra sí misma. Revista SAAP, 2(3), 658-660.

Múnera, L. (2008). Democracia y religión. El aporte de Alexis de Tocqueville. Universitas Philosophica, 25(50), 207-231.

Rahner, K. (1967). El oyente de la Palabra: fundamentos para una filosofía de la religión. (Trad. A. E. Lator Ros). Barcelona: Herder.

Rawls, J. (2012). Teoría de la Justicia. (Trad. Ma. Dolores González). Ciudad de México: Fondo de Cultura Económica.

Sen, A. (1999). Democracy as a universal value. Journal of Democracy, 10(3), 3-17.

Sorea, D. (2017). Some considerations on the future of secularization. Bulletin of the Transilvania University of Braşov. Series VII: Social Sciences and Law, 10(2), 93-106.

Scott, R. (2003). Strong religion. The Rise of fundamentalism around the world. Chicago: University of Chicago Press.

Spadaro, A. (2016). La diplomacia de Francisco. La misericordia como proceso político. Revista Selecciones de Teología, 1(2998), 1-21.

Touraine, A. (2001). ¿Qué es la democracia? Ciudad de México: Fondo de Cultura Económica. 